\title{
Application of Blockchain Technology in the Governance of Executive Corruption in Context of National Audit
}

\author{
Jie WANG, Xiaomei WANG* ${ }^{*}$, Hanxiu CHENG
}

\begin{abstract}
To reduce the impact of hidden corruption of the state-owned enterprise executives, first, this paper uses the difference-in-difference ( $D D)$ analysis method to build the $D D$ model in the context of national audit. Second, the study analyzes the impact of the operating performance of the state-owned enterprises on the enterprise value. Third, it discusses the impact of the executive power of the state-owned enterprises on the hidden corruption, and uses blockchain technology with decentralization and high transparency, and information not be tampered with to analyze the degree of information transparency in state-owned enterprises, thereby enhancing the existing audit mode and improving the audit efficiency, and further predicting the trend of hidden corruption for finding the characteristics of corruption as early as possible, and timely governing the corruption behaviors. The research results show that the greater the power of state-owned enterprise executives is, the lower the transparency of information is, the less sound the supervision mechanism is, and the easier the hidden corruption of state-owned enterprise executives will breed. Only by using blockchain technology to enhance the audit mode, ensure data integrity, improve audit efficiency, and decrease audit risk, can the corruption of the executives of state-owned enterprises be effectively curbed.
\end{abstract}

Keywords: blockchain; difference-in-difference model; hidden corruption; national audit; state-owned enterprises

\section{INTRODUCTION}

National audit is an important part of national governance, a kind of professional supervision in administrative supervision, and an indispensable part of financial administration. It monitors the operation track of economic activities from different aspects and links by reviewing, verifying, and evaluating the financial revenues and expenditures that comprehensively reflect economic activities. Moreover, it plays a comprehensive role in macro-control, which cannot be replaced by economic supervision methods. Meanwhile, several micro audits can be used to directly supervise the micro subjects to carry out economic activities in accordance with the law, thereby promoting the implementation of macro-control measures at the micro level and the improvement of micro economic benefits. Moreover, through the comprehensive analysis of a wide range of micro audit activities, it can reflect the situation to the decision-making part and put forward corresponding suggestions, thus promoting the improvement of macro-control and indirectly improving the macroeconomic benefits [1].

The corruption of senior executives can be divided into two forms: explicit corruption and hidden corruption. Explicit corruption is a direct violation of the relevant laws and regulations of the country, which is easy to be found, and once found, it is easy to be punished by the law. Hidden corruption is that executives use their power to seek personal benefits, which is not easy to be found and has a high degree of control. Hence, as the reform of state-owned enterprises is continuously accelerated, its system and mechanism, accounting treatment, business process and other aspects have changed greatly, which makes explicit corruption more common in state-owned enterprises [2].

The difference-in-difference $(D D)$ method is widely used in the evaluation of policy effect, and because its calculation model is simple and easy to use and the regression estimation method is mature, it has been showing a rapid development trend in recent years. Blockchain technology is a subversive innovation of computing mode after mainframe, personal computer, and internet. At present, most of them are applied to the financial and credit systems to ensure the safety of funds and prevent others from tampering with relevant information [3].

Therefore, considering the advantages of $D D$ method and blockchain technology, in the context of national audit, this paper uses $D D$ analysis method to analyze the impact of state-owned enterprises' operating performance on enterprise value. Moreover, the blockchain technology is utilized to analyze the transparency of financial data and information in state-owned enterprises, thereby improving the existing audit mode, enhancing the audit efficiency, and providing basis for the governance of hidden corruption of state-owned enterprises.

\section{LITERATURE REVIEW}

As the economy develops, audit has become an important work to ensure the healthy development of all walks of life. In some state-owned enterprises, the corruption of executives has been criticized, and its consequences have seriously restricted the economic and social development to a certain extent.

Jeppesen (2019) refuted the previous conclusion that "audit can prevent personnel corruption", aiming to analyze how various types of audit can help to combat corruption [4]. Meyer-Sahling et al. (2018) believed that in previous studies, the management of public officials themselves was mostly ignored, and corruption transactions would involve public officials. Therefore, 36 pieces of relevant literature were analyzed to obtain favorable evidence to prove the relationship between compensation structure and corruption degree in public official's management [5]. Habib et al. (2018) pointed out that there was a certain relationship among political relationship, financial report, and audit. In the process of investigation and research, these empirical data confirmed that the quality of financial report of politically connected companies could provide strong evidence [6]. Paterson et al. (2019) analyzed the criticality of anti-corruption policies and practices, explored corruption issues from the 
perspectives of transparency, audit, regulatory disclosure, governance, investor protection, and policies related to anti-corruption initiatives, and finally found that the adverse consequences of these behaviors would lead to human suffering and cost loss [7].

Simoyama et al. (2017) found it difficult for institutions in countries or regions with serious corruption problems to comply with relevant laws, especially in smaller institutions. Meantime, the national auditor could only select a smaller sample for audit according to the risk level, but not all accounts provided. There were some differences between audit and accounting time, so they proposed a non-technical framework based on blockchain to solve these problems. However, this research was only carried out in some countries, and was not extended in a wider range [8]. Pimentel et al. (2019) used blockchain technology to analyze the company's unaudited financial statements, but when introducing market research, it was found that auditors had not been able to deal with the complex and high-risk situation of this technology [9].

To sum up, after analyzing the previous literature, it is found that the application of blockchain in audit just begins. There are few pieces of literature, and few articles that combine $D D$ analysis and blockchain technology to the corruption governance of state-owned enterprise executives. Hence, in the context of national audit, the $D D$ analysis and blockchain technology are applied to the hidden corruption of state-owned enterprise executives, thereby minimizing the impact of hidden corruption on the executives of state-owned enterprises.

\section{METHOD}

\subsection{DD Analysis}

$D D$ method is a quantitative analysis method in econometrics, which is mainly used in the evaluation of policy effect in sociology. Its principle is to evaluate the change of observed factor $y$ in the two cases of policy occurrence and non-occurrence based on a counterfactual framework. If an exogenous policy shock divides the sample into two groups: Treat group with policy intervention and Control group without policy intervention. Before the policy shock, there is no significant difference in y between the Treat group and the Control group. Then, the change of $y$ in the Control group before and after the policy shock can be regarded as the situation of the Treat group without policy shock (counterfactual result). By comparing the change of $y(D 1)$ in the Treat group and $y$ (D2) in the Control group, the actual effect of policy shock $(D D=D 1-D 2)$ is obtained $[10,11]$

The model is shown in Eq. (1):

$Y_{\mathrm{it}}=\beta_{0}+\beta_{1} \cdot T_{i t}+\beta_{2} \cdot A_{i t}+\beta_{3} \cdot T_{i t} \cdot A_{t}+\varepsilon_{i t}$

where $T_{i}$ is the policy dummy variable, $A_{i}$ is the time dummy variable, $T_{i} \times A_{t}$ is the interaction term of the two, and $\beta_{3}$ is the $D D$ estimator. The changes of the two groups are shown in Eq. (2) and Eq. (3):

$$
\begin{aligned}
& D 1=E(Y \mid T=1, A=1)-E(Y \mid T=1, A=0)= \\
& =\left(\beta_{0}+\beta_{1}+\beta_{2}+\beta_{3}\right)-\left(\beta_{0}+\beta_{1}\right)=\beta_{2}+\beta_{3} \\
& D 2=E(Y \mid T=0, A=1)-E(Y \mid T=0, A=0)= \\
& =\left(\beta_{0}+\beta_{2}\right)-\left(\beta_{0}\right)=\beta_{2}
\end{aligned}
$$

Therefore, the actual effect of policy shock is shown in Eq. (4):

$$
D D=D 1-D 2=\left(\beta_{2}+\beta_{3}\right)-\beta_{2}=\beta_{3}
$$

Therefore, Tab. 1 is obtained:

Table $1 D D$ analysis

\begin{tabular}{|c|c|c|c|}
\hline & Before the implementation of the policy & After the implementation of the policy & \multicolumn{2}{|c|}{ Difference } \\
\hline Treat group & $\beta_{0}+\beta_{1}$ & $\beta_{0}+\beta_{1}+\beta_{2}+\beta_{3}$ & $\beta_{2}+\beta_{3}$ \\
\hline Control group & $\beta_{0}+\beta_{3}$ & $\beta_{2}$ \\
\hline Difference & $\beta_{1}+\beta_{3}$ & $\beta_{3} \cdot(D D)$ \\
\hline
\end{tabular}

\subsection{Blockchain}

Blockchain is a distributed database system, which can also be understood as a distributed ledger technology (DLT) maintained by multiple nodes, which is not easy to tamper with, difficult to forge, and traceable. Blockchain records all information of transactions. Once the data enters the blockchain, even internal staff cannot make any changes in the blockchain. This unchangeable feature does not come from the use of certain operations, but from the blockchain system and mechanism itself. This makes the blockchain technology simpler and more effective than other security technologies. Where fairness and honesty are needed, blockchain technology can be used $[12,13]$.

The blockchain divides the data into different blocks. Each block is linked to the previous block through specific information, and presents a complete set of data. The block header of each block contains a previous block hash value, that is, the value obtained from the hash function calculation of the block header of the previous block; each block will be linked by such hash value and the previous block ring to form a chain. The transaction information of the blockchain is randomly hashed into a hash binary tree called Merkle tree, whose root is included in the random hash value of the block.

In terms of technology, the core features of blockchain include the following three aspects:

First, block chain structure: each block has a time stamp, and each block contains the hash encryption information of the previous block to verify each transaction.

Second, multiple independent copy storage: each node of the blockchain system stores the same information.

Third, byzantine fault tolerance: tolerating less than $1 / 3$ nodes of malicious cheating or hacker attacks, the system can still work normally.

The core working mechanism of blockchain technology includes timestamp mechanism, consensus mechanism, privacy protection mechanism, and smart 
contract mechanism, which can make the transaction more efficient and less-cost, and solve the problem of trust risk $[14,15]$. Fig. 1 shows the infrastructure of blockchain technology:

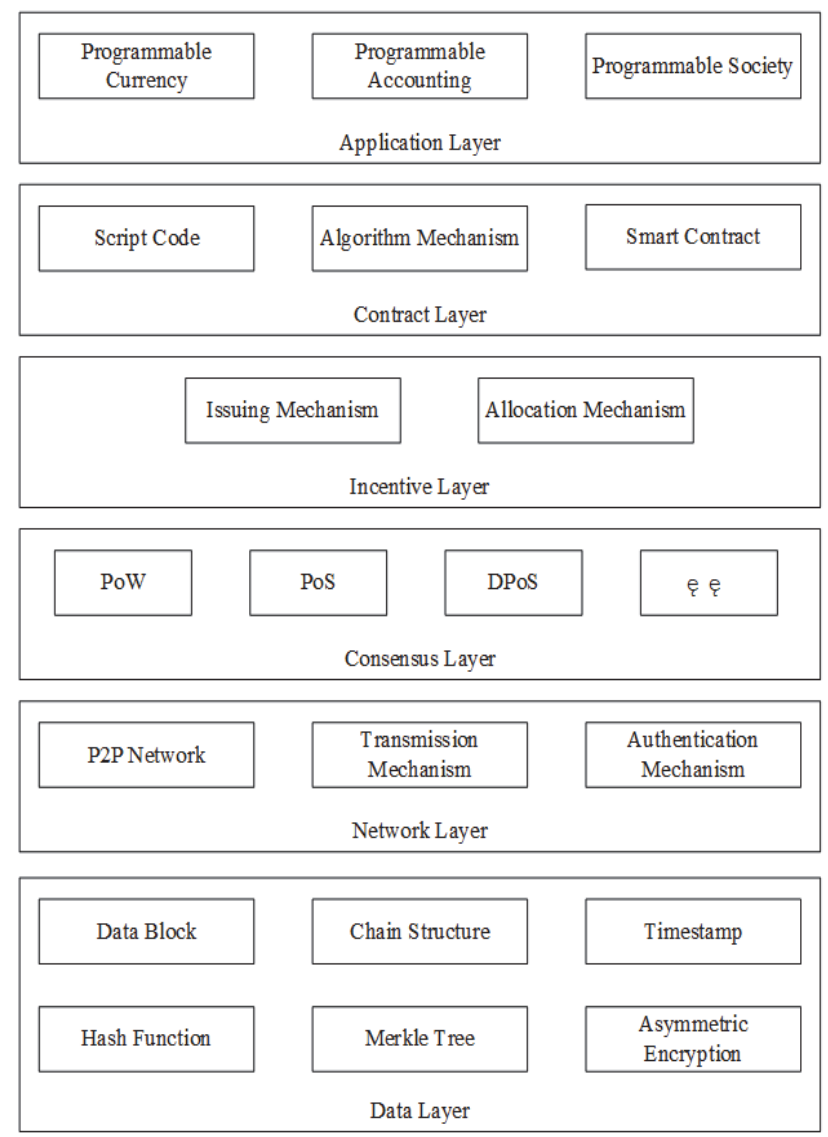

Figure 1 Infrastructure of blockchain technology

The timestamp mechanism generates a random hash value by real-time random hash operation on a group of data stored in blocks, and adds a time mark to it. Each timestamp incorporates its previous time stamp into its random hash value, and each subsequent time stamp enhances the previous time stamp. As a result, a complete traceability mechanism is formed to ensure that the data can be identified and tracked. Consensus mechanism mainly aims at improving the efficiency of system consensus with decentralized decision-making power, which can ensure the real-time, authenticity, security, and reliability of data on the blockchain $[16,17]$. The Merkel tree mechanism is the basic component of blockchain technology, which divides data blocks into smaller units, and then hashes each small unit of data again until the total number of remaining hashes is 1 , that is, the root hash. In this way, it is unnecessary to download each transaction and each block, and only verifying the root hash can prove the authenticity and validity of the data chain. This not only simplifies the data processing and query process, but also greatly improves the work efficiency and reduces the work cost. The smart contract mechanism is the core component of the blockchain, which can realize the active or passive processing of data, acceptance, storage, and transmission of value, to control and manage all kinds of intelligent assets on the chain and other functions $[18,19]$.

\section{EXPERIMENT}

\subsection{Governance of State-Owned Enterprises}

In the state-owned enterprises, there are many cases of senior executives' corruption, and the total number of cases is rising. Since the 18th National Congress of the Communist Party of China, the corruption of state-owned enterprises has shown a downward trend, which shows that the corruption storm has a certain inhibitory effect on corruption. The corporate governance of state-owned enterprises in China is the product of the transformation from planned economy to market economy. The stateowned enterprises are established by the initial publicprivate joint venture. Then, with the continuous transformation from planned economy to market economy, the management mode of state-owned enterprises is also changing from the original state-owned sole proprietorship to company system [20]. At present, there are still some problems in the governance structure of state-owned enterprises in China, such as the relatively high proportion of state-owned shares, the long principal-agent chain, and the phenomenon of insider control, the informal system of independent directors, and the unreasonable mechanism of selection, which makes it easy for some executives to conduct invisible transactions, thus breeding invisible corruption.

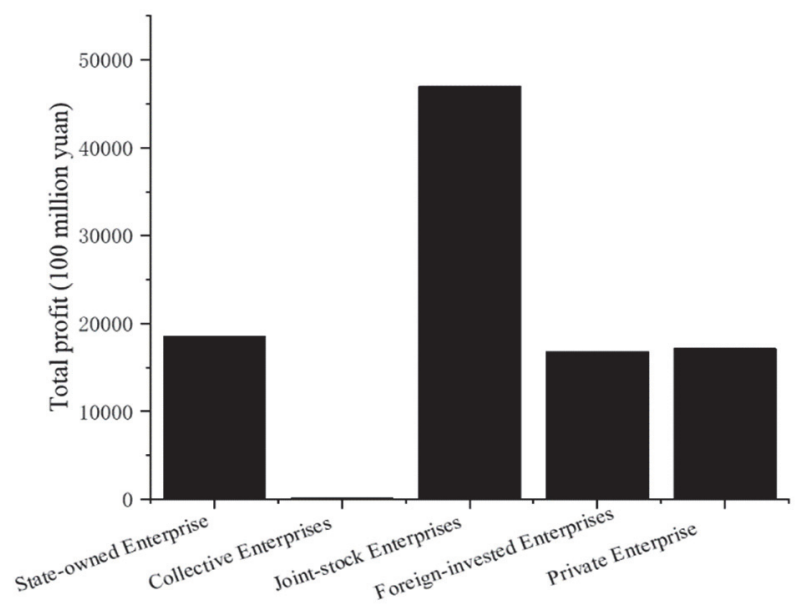

Figure 2 Profit statistics of Enterprises above Designated Size

In the context of China's transition economy, in order to ensure the dominant position of public ownership, many listed companies of state-owned enterprises introduce state-owned shares, legal person shares, and public circulation shares in the distribution of equity. The stateowned shares occupy an absolute control position, and have certain administrative color. Therefore, based on this problem, it is found that the governance conflicts in the governance process of state-owned enterprises mainly focus on the interest's conflicts between the state-owned controlling shareholders and the small and medium-sized shareholders. A large proportion of senior executives have certain administrative level, so in the selection process, they still maintain the traditional method, only considering their political future. Consequently, they are unable to focus on neither the profitability of the enterprise nor the improvement of operating efficiency. However, the existing independent director system is more formal. The majority shareholders can still control the board of 
directors and make it lack of independence, so it is difficult to play the expected independent supervision role. Hence, the corruption of senior executives occurs from time to time, especially hidden corruption [21]. According to statistics, in 2018, the total profits of Industrial Enterprises above Designated Size in China reached 6635.14 billion yuan, an increase of $10.3 \%$ over the previous year. Fig. 2 shows the statistics of the total profits of various enterprises.

The total profit realized by collective enterprises is the lowest, only 10.22 billion yuan. The total profit of stateowned holding enterprises has reached 1858.31 billion yuan, and the growth rate comparison is shown in Fig. 3.

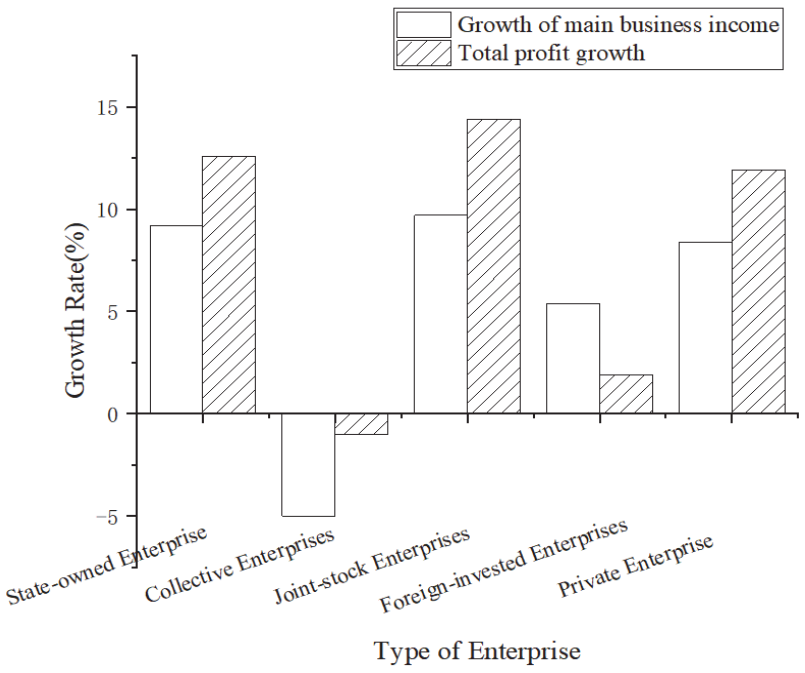

Figure 3 Growth rate of main business income and total profit of different types of enterprises in 2018

The business income and total profit of state-owned enterprises are generally high, which also shows that the governance of state-owned enterprises is conducive to the realization of their business income.

\subsection{Sample Selection}

A-share listed state-owned enterprises in the China Stock Market and Accounting Research database (CSMAR) from 2012 to 2016 are selected as the research objects. Before the data is studied, in order to ensure the validity of the data, the data will be preprocessed to eliminate the companies with incomplete data and the companies with extreme values. At last, there are 270 companies that meet the requirements. After that, excel is used for data processing and SPSS is used for analysis.

In the measurement of enterprise benefit, return on assets $(R O A)$ is used, which takes state-owned share proportion $(S S P)$, the sum of the shares of the top five shareholders (OCR5), shareholding ratio of the largest shareholder (CR1), and $Z$ as explanatory variables, enterprise scale $(S I Z E)$ and debt to asset ratio $(L E V)$ as control variables.

\subsection{Model Construction}

Many local governments have fiscal deficits. In order to increase employment and ensure social equity, they need to rely on state-owned enterprises. Thus, the managers of state-owned enterprises are given diversified goals in addition to economic growth. Meanwhile, more behaviors in economic activities will be interfered or supported by local governments, so the rights of managers will be increased, and also the possibility of corruption, which also gives executives more opportunities to obtain more implicit private interests.

National audit plays an important role in preventing and curbing corruption and abuse of administrative rights. In helping to investigate and deal with economic cases and corporate executives' corruption, it can improve the level of governance civilization and corporate governance efficiency. Hidden corruption is a kind of crime of corruption, which is hidden and hard to investigate. Due to the development of anti-corruption storm, most executives, driven by the interests of the economic people, will make up for its utility loss in other forms. Hidden corruption has become the ideal choice, and the most direct performance is excessive on-the-job consumption and excessive pay.

In order to make the information more transparent, the $D D$ model, which controls the individual of the company and the two-way fixed effect of the year, is utilized to analyze. First, establish a model based on the relationship between the proportion of state-owned shares and enterprise performance proposed by Chen Shuang Eq. (5):

$$
R O A=\beta_{0}+\beta_{1} \cdot S S P+\beta_{2} \cdot S S P^{2}+\beta_{3} \cdot S I Z E+\beta_{4} \cdot L E V+\varepsilon
$$

Second, when the first largest shareholder holds a low share, the ownership structure will be relatively scattered, and small shareholders may have speculative behavior, which is not conducive to the governance of state-owned enterprises. Therefore, considering the impact of the ownership structure on the company's performance, the relationship model between the first largest shareholder's shareholding ratio and the company's performance is established Eq. (6):

$$
R O A=\beta_{0}+\beta_{1} \cdot C R_{1}+\beta_{2} \cdot C R_{1}^{2}+\beta_{3} \cdot S I Z E+\beta_{4} \cdot L E V+\varepsilon
$$

Third, the shareholding ratio of the top five shareholders can approximately replace the degree of equity concentration of the enterprise. Generally, the enterprises with relatively concentrated equity tend to be more consistent when considering the interests than the enterprises with relatively decentralized equity, and can make decisions beneficial to the company. Therefore, the relationship model between the square sum of the top five shareholders' shareholding ratio and corporate performance is established Eq. (7):

$$
R O A=\beta_{0}+\beta_{1} \cdot O C R_{5}+\beta_{2} \cdot S I Z E+\beta_{3} \cdot L E V+\varepsilon
$$

Finally, by analyzing the shareholding ratio of the second largest shareholder and the first largest shareholder, it can be found that there are mutual constraints between them. When one party makes decisions that are not conducive to the development of the enterprise, the other party has the right to veto, thus protecting the company's interests. In general, the larger the proportion of the two is, the stronger the binding force of the second shareholder on 
the first shareholder is. Therefore, it is necessary to analyze the relationship between the shareholding ratio and enterprise performance, and establish a relationship model Eq. (8):

$$
R O A=\beta_{0}+\beta_{1} \cdot Z+\beta_{2} \cdot S I Z E+\beta_{3} \cdot L E V+\varepsilon
$$

\section{RESULTS AND DISCUSSION}

According to the statistical analysis of variables, the descriptive statistical results of variables in Fig. 4 are obtained.

Fig. 4 shows that the average $R O A$ reaches 1.25. SSP selected by the sample is quite different, and the standard deviation is 0.16 , which indicates that their discrete degree is not high, and only individual samples are quite different. The selected samples are more reasonable and acceptable. From other variables, there is a large gap between the maximum and minimum values of $C R 1$, with an overall mean value of about 0.4 , which shows that the largest shareholder holds a relatively high proportion. The difference between the maximum value and the minimum value of $O C R 5$ is second only to $C R 1$, which shows that the internal equity of the selected sample is relatively concentrated. The difference between the maximum value and the minimum value of $Z$ value is large, and the average value is small, which shows that the internal equity balance degree of the sample is low.

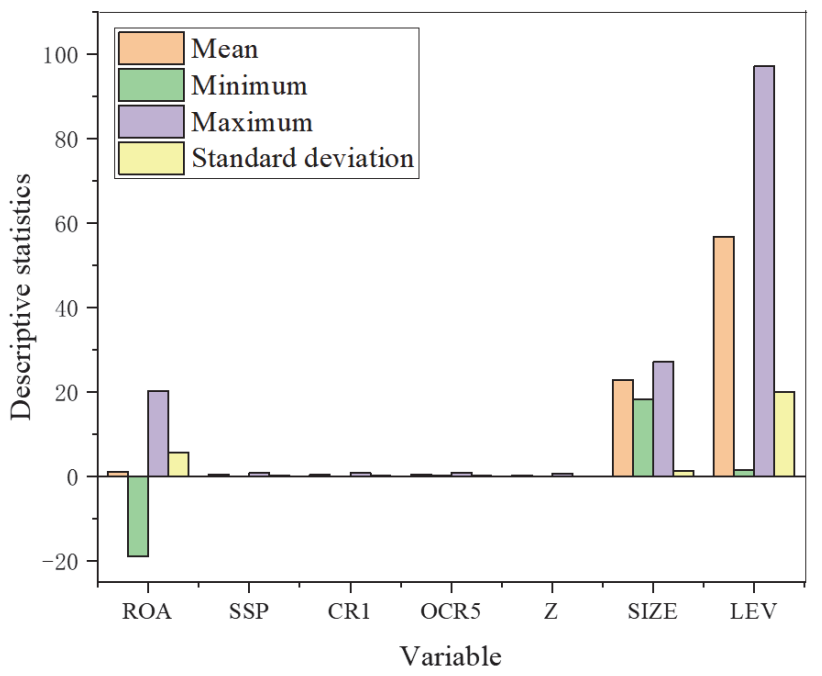

Figure 4 Descriptive statistical results of variables

When regression analysis is carried out among these variables, it is found that the $t$-statistics will change with different significance levels. For the model of Eq. (5), the data in Tab. 2 are obtained at 1\% significance level.

Table 2 Regression results of $S S P$ and enterprise performance model

\begin{tabular}{|c|c|c|c|c|c|c|c|c|c|c|c|c|}
\hline Variables & $S S P$ & $S S P 2$ & $C R 1$ & $C R 12$ & OCR5 & $Z$ & SIZE & $L E V$ & $R^{2}$ & Adjusted $R$ & $F$ \\
\hline & 0.0877 & -0.080 & - & - & - & - & 1.2796 & -0.155 & 0.425 & 0.415 & 22.160 \\
\hline
\end{tabular}

For the model of Eq. (6), when the significance level is $10 \%$, the corresponding $C R 1$ is 0.095 , while $C R 12$ is -0.08 ; when the significance level is $1 \%$, the SIZE is 1.330 , $L E V$ is 0.155 , and the final $F$ is 22.230 .

For the model of Eq. (7), when the significance level is $5 \%, O C R 5$ is 0.040 ; when the significance level is $1 \%$, its $S I Z E$ is $1.130, L E V$ is $-0.152, R 2$ is 0.633 , adjusted $R 2$ is 0.623 , and $F$ is 28.801 .

For the model of Eq. (8), when the significance level is $1 \%, Z$ is 0.964, SIZE is $1.390, L E V$ is $-0.153, R 2$ is 0.833 , adjusted $R 2$ is 0.823 , and $F$ is 28.271 .

Therefore, $R 2$, adjusted $R 2$, and $F$ - value statistics of each model are all within the acceptable range, and their fitness meets the requirements and passes the $F$ - test.

On this basis, it is known too high or too low stateowned shares are not conducive to the improvement of the performance of state-owned enterprises. At the significant level of $10 \%, C R 1$ and its square term show that there is Ushaped relationship between the first largest shareholder and corporate performance. Too high or too low first largest shareholder's shareholding ratio is not conducive to the improvement of corporate performance. In the test of the relationship between $O C R 5$ and corporate performance, it is seen that the coefficient of equity concentration is positive, and $P$ is positive, which means that equity concentration is positively related to corporate performance at the significance level of 5\%. Moderate concentration of equity is conducive to the improvement of corporate performance. The coefficient of $Z$ index is positive at the significance level of $1 \%$. Equity balance is conducive to the improvement of enterprise performance. Hence, the internal audit and the turnover rate of total assets under the governance of state-owned enterprises are analyzed, and the average test results are shown in Fig. 5.

Fig. 5 shows that the Difference value of the Treat group before and after the governance is 0.8070 , while that of the Control group is 0.0296 . Therefore, $D D$ currently is 0.7774 . However, the significant level is inconsistent at this time. Hence, the single variable analysis of internal audit and total asset yield is shown in Fig. 6.

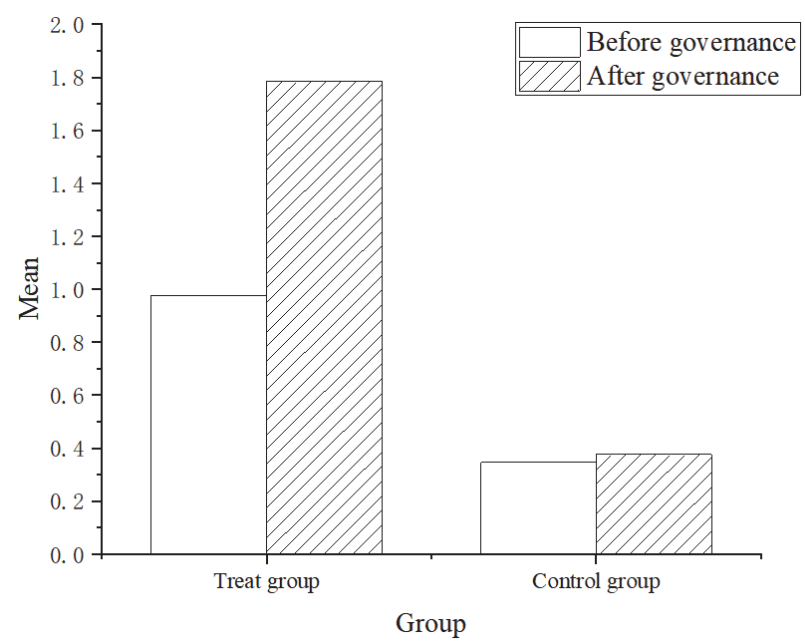

Figure 5 Internal audit and analysis of turnover rate of total assets

Fig. 6 suggests that the average value obtained is significant at the level of $1 \%$. At this time, the $D D$ value between the Treat group and the Control group is 0.0533 . There is a greater change after governance than before, indicating that internal audit has a higher help for the 
profitability of enterprises.

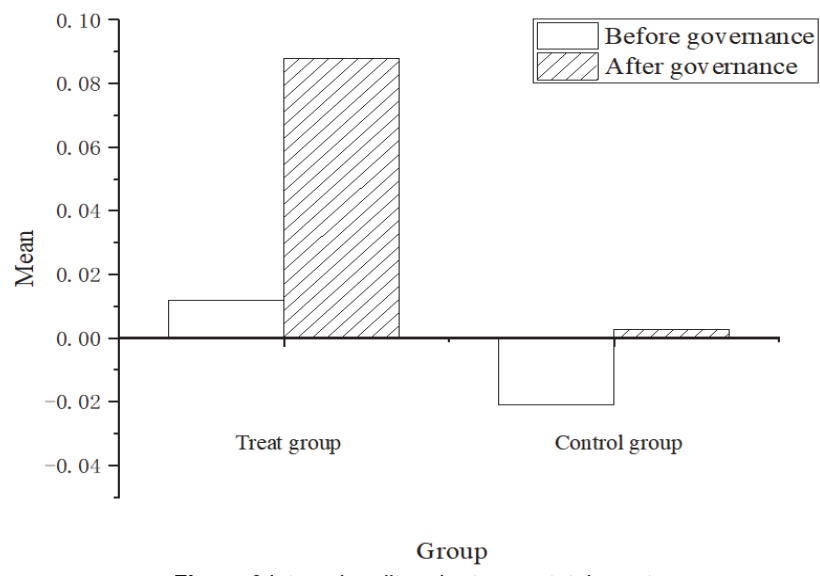

Figure 6 Internal audit and return on total assets

When applying blockchain technology to analyze the relevant information of state-owned enterprises, it is found that the technology can improve the system operation efficiency and minimize the cost while ensuring the information security. The transaction records of blockchain are transparent, and there will be no privacy. This information can also be viewed, but it cannot be modified, so it also provides strong evidence for government supervision. Meanwhile, the timestamp in blockchain technology is immutable, so it is not easy to tamper with, which is of great help to fight against counterfeiting and information rectification. From the perspective of trust, all rules in the blockchain have been implemented in the form of programs. The technology adopts a complete redundancy strategy to ensure that all the complete nodes have complete data. To change the existing data, it is necessary to modify all the data, but it seems impossible, which reduces the risk of fraud.

As an important part of the governance of state-owned enterprises, the most important thing is to solve the security problem, not only prevent corruption clues from missing in the data flow, but also prevent data from being tampered, hidden, or destroyed. Second, solve the confidentiality of data. As invisible corruption is not easy to be detected, it is necessary to compare and verify the reported information of corruption with corruption, and more links are also prone to the risk of disclosure. Moreover, the use of information technology can better solve the corruption governance work and improve the existing audit mode. From the big data-based audit 3.0 to the currently semiautomatic and automatic audit 4.0, the use of sensors, the Internet of things, and radio frequency identification for audit is characterized by the generation and application of distributed ledger represented by blockchain. Fig. 7 shows the information interaction mode of each audit stage:

Among them, Fig. $7 \mathrm{a}$ shows the information interaction mode of audit 1.0 and 2.0, mainly simple account book and double account book, with serious centralization; Fig. 7b shows the big data-based audit of audit 3.0, with digital account book and decentralized mode; Fig. 7c shows the information interaction mode of audit 4.0, mainly distributed account book, semi-automatic and automatic audit process.

As can be seen from Fig. 7, the information interaction mode in this stage is distributed, and the account book adopts distributed mode. The cost of information identification in this form is far lower than that in the first three stages, but the cost of information recording is higher than that in the previous three stages. Blockchain technology also realizes the transformation from a closed system to a real-time and transparent distributed system, ensuring the authenticity and effectiveness of business.

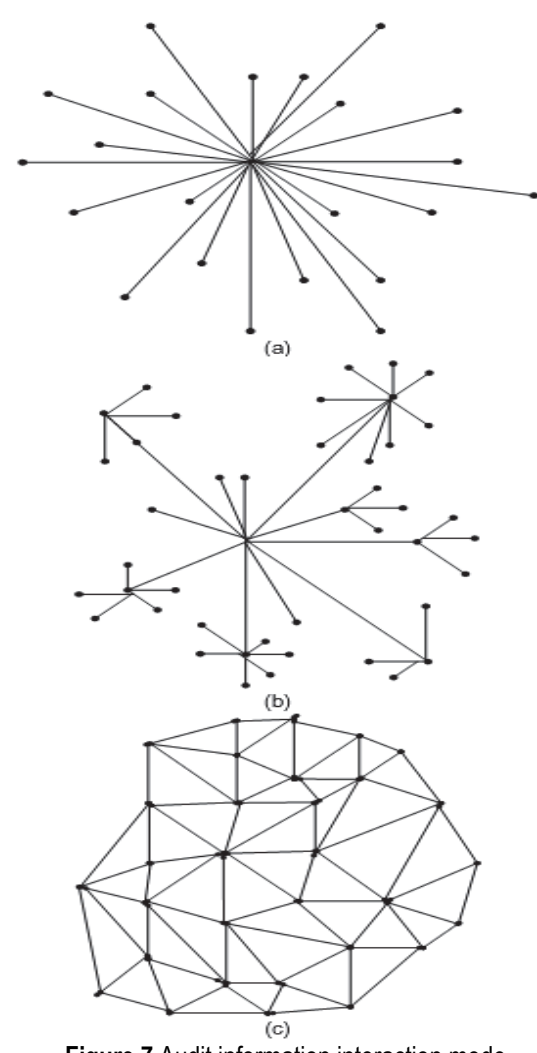

Figure 7 Audit information interaction mode

To sum up, when using the $D D$ analysis method to analyze the state-owned enterprises, it is found that the proportion of state-owned shares, OCR5, the proportion of the first largest shareholder, and the proportion of the second largest shareholder and the first largest shareholder all need to ensure an appropriate proportion, thus avoiding the phenomenon of hidden corruption of senior executives when the proportion of state-owned shares is too large. In the process of governance of state-owned enterprises, it is supposed to focus on the hidden corruption of executives in addition to the ownership structure. The use of blockchain technology can ensure the security and transparency of distributed account data, thereby preventing the occurrence of hidden corruption of stateowned enterprise executives to a certain extent.

\section{CONCLUSION}

The $D D$ analysis method is used to build the model of state-owned enterprises' equity problems, for exploring the relationship between equity problems and business performance, and further analyzing the impact of business performance on enterprise value. On this basis, the situation of executives' implicit corruption in the governance of state-owned enterprises is analyzed, and the existing audit methods are discussed by using blockchain technology. It points out that the audit 4.0 stage of 
distributed account application represented by blockchain technology can ensure its security and transparency and not being tampered with to a certain extent. However, in the research process, this paper does not make a specific case analysis of the application of blockchain technology in the governance process of state-owned enterprise executives' hidden corruption, which will be further refined in the later research, thereby making the governance work of executives' hidden corruption more intelligent and efficient. In the context of national audit, the combination of $D D$ analysis and blockchain technology to deal with the hidden corruption of the executives of state-owned enterprises is of great significance to improve the existing audit methods, and to establish a new anti-corruption management system. Maximizing the role of big data in anti-corruption work and using blockchain technology also aims at preventing corruption as much as possible, thereby creating a healthy and honest enterprise. Meanwhile, it can also be used for reference for the governance of corruption of relevant national institutions.

\section{Acknowledgments}

The work is supported by the 2017 general project of humanities and social sciences research in universities in Anhui province (project number: SK2017B05); The 2017 major project of humanities and social sciences research in universities in Anhui province (project number: SK2017A0417); The 2019 project of ChuZhou University (project number: RJZ01)

\section{REFERENCES}

[1] Cameran, M., Prencipe, A., \& Trombetta, M. (2016). Mandatory audit firm rotation and audit quality. European accounting review, 25(1), 35-58. https://doi.org/10.1080/09638180.2014.921446

[2] Daiser, P., Ysa, T., \& Schmitt, D. (2017). Corporate governance of state-owned enterprises: a systematic analysis of empirical literature. International Journal of Public Sector Management, 30(5), 447-466. https://doi.org/10.1108/IJPSM-10-2016-0163

[3] Bloche, M. G. (2016). Scandal as a sentinel eventRecognizing hidden Cost-quality trade-offs. New England Journal of Medicine, 374(11), 1001-1003. https://doi.org/10.1056/NEJMp1502629

[4] Jeppesen, K. K. (2019). The role of auditing in the fight against corruption. The British Accounting Review, 51(5), 100798. https://doi.org/10.1016/j.bar.2018.06.001

[5] Meyer-Sahling, J. H., Mikkelsen, K. S., \& Schuster, C. (2018). Civil service management and corruption: What we know and what we don't. Public Administration, 96(2), 276285. https://doi.org/10.1111/padm.12404

[6] Habib, A., Ranasinghe, D., Muhammadi, A. H., \& Islam, A. (2018). Political connections, financial reporting and auditing: Survey of the empirical literature. Journal of International Accounting, Auditing and Taxation, 31, 37-51. https://doi.org/10.1016/j.intaccaudtax.2018.05.002

[7] Paterson, A. S., Changwony, F., \& Miller, P. B. (2019). Accounting control, governance and anti-corruption initiatives in public sector organisations. https://doi.org/10.1016/j.bar.2019.100844

[8] Simoyama, F. D. O., Grigg, I., Bueno, R. L. P., \& Oliveira, L. C. D. (2017). Triple entry ledgers with blockchain for auditing. International Journal of Auditing Technology, 3(3), 163-183. https://doi.org/10.1504/IJAUDIT.2017.086741
[9] Pimentel, E., Boulianne, E., Eskandari, S., \& Clark, J. (2019). Systemizing the Challenges of Auditing Blockchain-Based Assets. Available at SSRN 3359985. https://doi.org/10.2139/ssrn.3359985

[10] Prendergast, G., Paliwal, A., \& Mazodier, M. (2016). The Hidden Factors Behind Sponsorship and Image Transfer: Considerations for Bilateral Image Transfer Among Sponsors and Events. Journal of Advertising Research, 56(2), 132-135. https://doi.org/10.2501/JAR-2016-026

[11] Nguyen, T. V., Ho, B. D., Le, C. Q., \& Nguyen, H. V. (2016). Strategic and transactional costs of corruption: perspectives from Vietnamese firms. Crime, Law and Social Change, 65(4-5), 351-374. https://doi.org/10.1007/s10611-016-9609-7

[12] Treleaven, P., Brown, R. G., \& Yang, D. (2017). Blockchain technology in finance. Computer, 50(9), 14-17 https://doi.org/10.1109/MC.2017.3571047

[13] Meng, W., Tischhauser, E. W., Wang, Q., Wang, Y., \& Han, J. (2018). When intrusion detection meets blockchain technology: a review. Ieee Access, 6, 10179-10188. https://doi.org/10.1109/ACCESS.2018.2799854

[14] Hawlitschek, F., Notheisen, B., \& Teubner, T. (2018). The limits of trust-free systems: A literature review on blockchain technology and trust in the sharing economy. Electronic commerce research and applications, 29, 50-63. https://doi.org/10.1016/j.elerap.2018.03.005

[15] Peck, M. E. (2017). Blockchain world-Do you need a blockchain? This chart will tell you if the technology can solve your problem. IEEE Spectrum, 54(10), 38-60. https://doi.org/10.1109/MSPEC.2017.8048838

[16] Yeoh, P. (2017). Regulatory issues in blockchain technology. Journal of Financial Regulation and Compliance, 25(2), 196-208. https://doi.org/10.1108/JFRC-08-2016-0068

[17] Eyal, I. (2017). Blockchain technology: Transforming libertarian cryptocurrency dreams to finance and banking realities. Computer, 50(9), 38-49. https://doi.org/10.1109/MC.2017.3571042

[18] Francisco, K. \& Swanson, D. (2018). The supply chain has no clothes: Technology adoption of blockchain for supply chain transparency. Logistics, 2(1), 2. https://doi.org/10.3390/logistics2010002

[19] Francisco, K. \& Swanson, D. (2018). The supply chain has no clothes: Technology adoption of blockchain for supply chain transparency. Logistics, 2(1), 2. https://doi.org/10.3390/logistics2010002

[20] Lu, X., Ke, S., Cheng, T., \& Chen, T. (2018). The impacts of large-scale OFI on grains import: Empirical research with double difference method. Land use policy, 76, 352-358. https://doi.org/10.1016/j.landusepol.2018.05.023

[21] Adusah-Poku, F. \& Takeuchi, K. (2019). Household energy expenditure in Ghana: A double-hurdle model approach. World Development, 117, 266-277. https://doi.org/10.1016/j.worlddev.2019.01.018

Contact information:

\section{Jie WANG}

Nanjing University of Science and Technology

School of Economics and Management, China

\section{Xiaomei WANG}

(Corresponding author)

Chuzhou University,

School of Economics and Management,

No. 2, Langya West Road, 239000 Chuzhou, Anhui Province, China

E-mail: wangxiaomeng_czu@163.com

\section{Hanxiu CHENG}

Nanjing University of Science and Technology,

School of Economics and Management, China 